\title{
Selective Attention to Visual Stimuli Using Auditory Distractors Is Altered in Alpha-9 Nicotinic Receptor Subunit Knock-Out Mice
}

\author{
@Gonzalo Terreros, ${ }^{1}$ Pascal Jorratt, ${ }^{1}{ }^{\circledR}$ Cristian Aedo, ${ }^{1,3}{ }^{\circledR}$ Ana Belén Elgoyhen, ${ }^{4,5}$ and $\oplus^{-P a u l ~ H . ~ D e l a n o ~}{ }^{1,2}$ \\ ${ }^{1}$ Programa de Fisiología y Biofísica, ICBM, Facultad de Medicina, Universidad de Chile, Santiago 8380453, Chile, ${ }^{2}$ Departamento de Otorrinolaringología, \\ Hospital Clínico de la Universidad de Chile, Santiago 8380456, Chile, 3 Departamento de Tecnología Médica, Facultad de Medicina, Universidad de Chile, \\ Santiago 8380455, Chile, ${ }^{4}$ Instituto de Investigaciones en Ingeniería Genética y Biología Molecular, Dr. Héctor N. Torres, Consejo Nacional de \\ Investigaciones Científicas y Técnicas, Buenos Aires 1428, Argentina, and ${ }^{5}$ Instituto de Farmacología, Facultad de Medicina, Universidad de Buenos Aires, \\ Buenos Aires 1122, Argentina
}

During selective attention, subjects voluntarily focus their cognitive resources on a specific stimulus while ignoring others. Top-down filtering of peripheral sensory responses by higher structures of the brain has been proposed as one of the mechanisms responsible for selective attention. A prerequisite to accomplish top-down modulation of the activity of peripheral structures is the presence of corticofugal pathways. The mammalian auditory efferent system is a unique neural network that originates in the auditory cortex and projects to the cochlear receptor through the olivocochlear bundle, and it has been proposed to function as a top-down filter of peripheral auditory responses during attention to cross-modal stimuli. However, to date, there is no conclusive evidence of the involvement of olivocochlear neurons in selective attention paradigms. Here, we trained wild-type and $\alpha-9$ nicotinic receptor subunit knock-out (K0) mice, which lack cholinergic transmission between medial olivocochlear neurons and outer hair cells, in a two-choice visual discrimination task and studied the behavioral consequences of adding different types of auditory distractors. In addition, we evaluated the effects of contralateral noise on auditory nerve responses as a measure of the individual strength of the olivocochlear reflex. We demonstrate that KO mice have a reduced olivocochlear reflex strength and perform poorly in a visual selective attention paradigm. These results confirm that an intact medial olivocochlear transmission aids in ignoring auditory distraction during selective attention to visual stimuli.

Key words: attention; auditory distractors; auditory efferent; nicotinic receptors; olivocochlear; top-down

\section{Significance Statement}

The auditory efferent system is a neural network that originates in the auditory cortex and projects to the cochlear receptor through the olivocochlear system. It has been proposed to function as a top-down filter of peripheral auditory responses during attention to cross-modal stimuli. However, to date, there is no conclusive evidence of the involvement of olivocochlear neurons in selective attention paradigms. Here, we studied the behavioral consequences of adding different types of auditory distractors in a visual selective attention task in wild-type and $\alpha$-9 nicotinic receptor knock-out (KO) mice. We demonstrate that KO mice perform poorly in the selective attention paradigm and that an intact medial olivocochlear transmission aids in ignoring auditory distractors during attention.

\section{Introduction}

In the brain of a behaving animal, there is a permanent balance between the activity of top-down (voluntary or goal directed) and

Received Nov. 9, 2015; revised May 6, 2016; accepted May 26, 2016.

Author contributions: G.T., A.B.E., and P.H.D. designed research; G.T., P.J., and C.A. performed research; A.B.E. and P.H.D. contributed unpublished reagents/analytic tools; G.T., P.J., C.A., and P.H.D. analyzed data; G.T., A.B.E., and P.H.D. wrote the paper.

This work was supported by Fondecyt (Grant 3130635 to G.T.) and Fundación Guillermo Puelma. We thank Luis Robles for valuable comments, Felipe Moreno-Gómez for the bootstrap analysis of data, Fernando Vergara for technical assistance, and Dr. Douglas Vetter for providing WT and $\alpha 9$-nAChR K0 mice. bottom-up (involuntary or stimulus directed) attention networks. Paradigms studying selective attention are models of predominant top-down attention processing in which subjects voluntarily focus their cognitive resources on a specific stimulus while ignoring others (Fritz et al., 2007). The filter theory of

\section{The authors declare no competing financial interests.}

Correspondence should be addressed to Paul H. Delano, Independencia 1027, Programa de Fisiología y Biofísica, ICBM, Facultad de Medicina, Universidad de Chile, Santiago 8380453, Chile. E-mail: pdelano@med.uchile.cl.

DOI:10.1523/JNEUROSCI.4031-15.2016

Copyright $\odot 2016$ the authors $\quad 0270-6474 / 16 / 367198-12 \$ 15.00 / 0$ 
attention (Broadbent, 1958) has been proposed as one of the neural substrates for top-down attention mechanisms. According to this model, attention-related changes in the neural activity of higher stages of the brain can modulate the activity of more initial structures in the nervous system, acting as biological filters of the responses to irrelevant stimuli (Gilbert and Sigman, 2007).

A prerequisite to accomplish top-down modulation of the activity of peripheral structures is the presence of corticofugal pathways. The mammalian auditory efferent system is a unique neural network that originates in the auditory cortex and projects to the cochlear receptor through the olivocochlear (OC) bundle (Robles and Delano, 2008; Terreros and Delano, 2015). The OC system comprises medial (MOC) and lateral (LOC) olivocochlear neurons located in the brainstem (Warr and Guinan, 1979). MOC neurons make synapses with auditory receptor cells, the outer hair cells (OHC) of the cochlea, and LOC neurons make synapses with type I auditory nerve neurons (Guinan, 1996). MOC neurons release acetylcholine and activate nicotinic receptors assembled from $\alpha 9$ and $\alpha 10$ subunits located in OHCs (Elgoyhen et al., 1994, 2001). Importantly, for the CNS, they are the final and mandatory pathway to regulate $\mathrm{OHC}$ responses $(\mathrm{Mu}-$ rugasu and Russell, 1996; Cooper and Guinan, 2003). Therefore, all corticofugal modulation of $\mathrm{OHC}$ responses must be transmitted through MOC synapses (Katz and Elgoyhen, 2014).

The auditory efferent system has been proposed to function as a top-down filter of peripheral auditory responses during attention to cross-modal stimuli (Hernandez-Peón et al., 1956; Oatman, 1971; Delano et al., 2007; Wittekindt et al., 2014; Walsh et al., 2015). For instance, Wittekindt et al. (2014) showed in human subjects that, during periods of visual attention to Gabor patches, there is a reduction in the amplitude of distortion product otoacoustic emissions (DPOAE), indicative of a reduction of OHCbased cochlear amplification. Similarly, reductions in the amplitude of auditory nerve responses to click and tone $(\mathrm{C}+\mathrm{T})$ distractors during selective attention to visual stimuli have been obtained in cats and chinchillas (Oatman, 1971; Delano et al. 2007). In the latter work, we found cochlear receptor potential increases (cochlear microphonics, CM) concomitant to reductions of auditory-nerve compound action potentials (CAP) during visual attention. These attentional effects were most likely produced by activation of MOC neurons because the electrical stimulation of MOC fibers produces opposite effects in CAP and CM amplitudes (Elgueda et al., 2011). However, to date, there is no conclusive evidence of the involvement of MOC neurons in selective attention paradigms.

In the present work, we trained wild-type (WT) and $\alpha-9$ nicotinic receptor subunit $(\alpha 9$-nAChR) knock-out (KO) mice, which lack cholinergic transmission between $\mathrm{MOC}$ and $\mathrm{OHC}$ (Vetter et al., 1999), in a two-choice visual discrimination task and studied the behavioral consequences of adding auditory distractors. We demonstrate that $\alpha 9$-nAChR KO mice perform poorly in a visual discrimination task, showing that an intact MOC efferent-OHC synaptic transmission aids in efficiently reducing cochlear sensitivity during selective attention to visual stimuli.

\section{Materials and Methods}

Animals. Visual discrimination data were obtained from $17 \alpha 9$-nAChR $\mathrm{KO}$ and $15 \mathrm{WT}$ adult male mice, aged between 60 and $80 \mathrm{~d}$ and weighing between 22 and $30 \mathrm{~g}$ at the start of the behavioral training. $\alpha 9$-nAChR KO mice on a 129S6/SvEv backcrossed to CBA/CaJ background (Vetter et al., 1999) and WT littermates were generously provided by Dr. Douglas Vetter from the University of Mississippi. Genotypes were confirmed before and after the behavioral training by PCR screening of genomic DNA extracted and purified from the tail. All mice were housed in groups of two in polycarbonate cages $(27.5 \mathrm{~cm}$ long, $16.5 \mathrm{~cm}$ wide, and $13.0 \mathrm{~cm}$ high) for the complete duration of the experiment with a $12 \mathrm{~h} \mathrm{light/dark}$ cycle (lights on at $0800 \mathrm{~h}$ ) in a temperature-controlled room $\left(22 \pm 2^{\circ} \mathrm{C}\right)$. During all of the experimental period, mice were given water ad libitum and were food deprived, maintaining $84-92 \%$ of their free-feeding weight. Mice were manipulated and weighed every day by the same investigator. All procedures were approved by the local committee of Bioethics (Comité de Bioética Animal permit number \#0548 Facultad de Medicina, Universidad de Chile) and were performed in accordance with the Guidelines for the Care and Use of Laboratory Animals (publication number 86-23, National Institutes of Health, revised 1996).

Training procedures. Two experimenters blinded to the genotype of the animals performed the behavioral procedures. Mice were trained in a two-choice visual discrimination task similar to those that we used previously to assess visual attention in rats (Hamame et al., 2006, 2008) and chinchillas (Delano et al., 2007). The experimental protocol was performed in an operant mesh cage $(17 \mathrm{~cm}$ long, $20 \mathrm{~cm}$ wide, and $28 \mathrm{~cm}$ high) located inside a double-walled sound-attenuating room $1 \mathrm{~m}$ above the room floor and $1.4 \mathrm{~m}$ from the ceiling. The front panel of the cage had three different lights: a central light (neutral cue) above a magazine food dispenser and two lateral lights (targets) under which there were two levers located $1 \mathrm{~cm}$ above the cage floor (Fig. 1A). The operant cage, stimulus presentation, and data acquisition were controlled by a custommade computer program written in the $\mathrm{C}$ programming language (developed in LabWindows/CVI 9.0 environment; National Instruments) and a digital interface.

Each trial began with the onset of a neutral cue (central light or warning period) with a duration of $2 \mathrm{~s}$, after which the right or left target light was turned on randomly for a period of $0.5 \mathrm{~s}$ (Fig. $1 B$ ). Mice were trained to respond by pressing the corresponding lever. A response in the lever located below the target light made during the response period (within $5 \mathrm{~s}$ from the onset of the target light) was defined as a correct response and was rewarded with a $15 \mathrm{mg}$ precision pellet (Bioserv). Incorrect responses were defined as responses made during the response period in the lever opposite to the target light. The intertrial interval (ITI) period varied randomly between 5 and $11 \mathrm{~s}$. Central light, incorrect, or ITI responses were punished with a $12 \mathrm{~s}$ timeout period during which all lights were turned off. Trials in which mice did not respond to the cue or target lights were defined as omission trials and were not punished. The behavioral variables measured were as follows: latency of correct lever-pressing responses (time between the onset of the target light and the lever-pressing response), accuracy ([correct responses/(correct responses + incorrect responses) $] \times 100$ ), number of responses during the warning and ITI periods, and number of omitted trials. To initiate the experimental protocol phase, all mice were trained until they reached a behavioral criterion of at least $70 \%$ accuracy for 3 consecutive days. The mean age of WT and $\mathrm{KO}$ mice at the beginning of the experimental protocol was $144.7 \pm$ 8.0 (mean $\pm \mathrm{SD}$ ) and $145.4 \pm 10.3 \mathrm{~d}$, respectively (WT: $4.82 \pm 0.26$ months; KO: $4.85 \pm 0.34$ months).

Experimental protocol. After mice reached the behavioral criterion, they were recruited in the experimental protocol. Behavioral performance was evaluated for $12 \mathrm{~d}$ divided into 4 periods of $3 \mathrm{~d}$ (Fig. 1C). Mice performed 110 trials each day of the protocol. For the analysis of possible effects along sessions, trials were divided into five blocks of 22 trials. In the first $3 \mathrm{~d}$ (predistractor period, PRE), mice performed the 2-choice visual discrimination task without auditory distractors. During days 4-9, mice did the visual discrimination task in the presence of two different auditory distractors: (1) days 4-6: clicks and $15 \mathrm{kHz}$ tones presented at $\sim 65 \mathrm{~dB}$ SPL $(\mathrm{C}+\mathrm{T})$ and $(2)$ days $7-9$ : broadband noise presented at $\sim 90$ $\mathrm{dB}$ SPL (BBN). Finally, in the last $3 \mathrm{~d}$ of the protocol (days 10-12, postdistractor period, POST), mice were again evaluated in the visual discrimination task without auditory distractors (Fig. $1 B, C$ ).

Auditory distractors. Two different auditory distractors were used in the behavioral protocol: (1) clicks ( $100 \mu$ s wide) and $15 \mathrm{kHz}$ tones and (2) BBN (5-40 kHz). All acoustic stimuli were digitally generated at 100 $\mathrm{kHz}$ with a National Instruments Board (PC-MIO-16E4). Tones and $\mathrm{BBN}$ had a $5 \mathrm{~ms}$ ramp (rise/fall) and a total duration of $150 \mathrm{~ms}$. To 

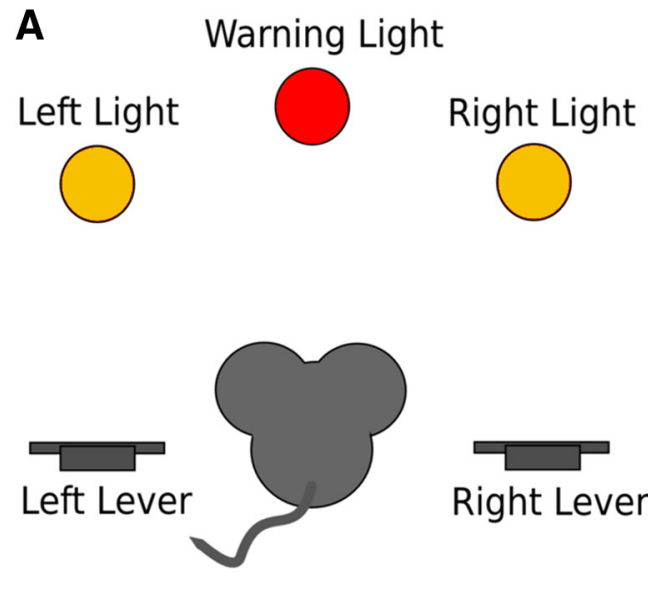

B

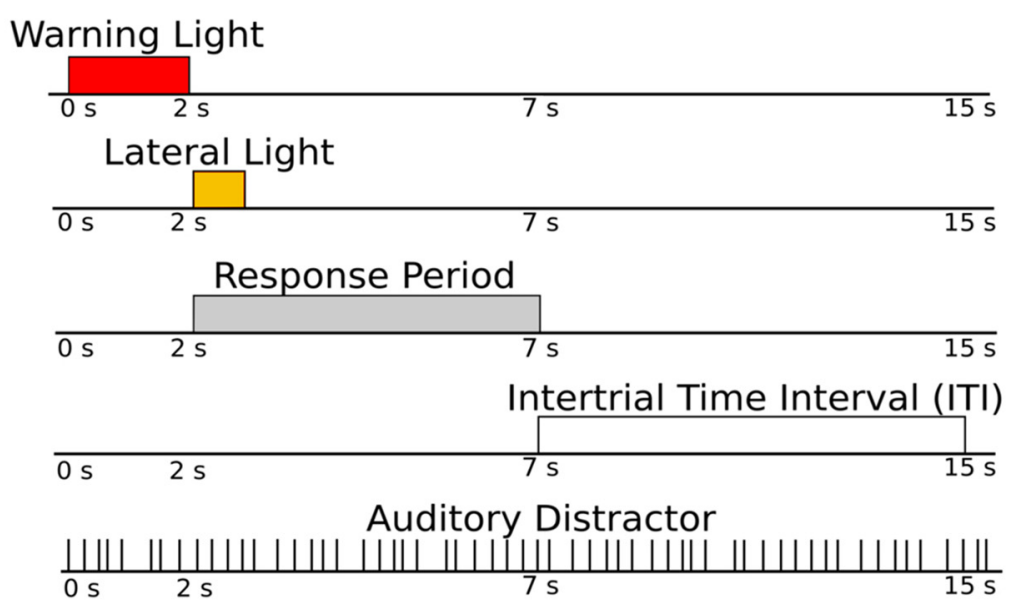

C

\begin{tabular}{|c|c|c|c|}
\hline Pre Distractor & $C+T$ & BBN & Post Distractor \\
\hline $\begin{array}{c}\text { Visual } \\
\text { Discrimination }\end{array}$ & $\begin{array}{c}\text { Click + Tone } \\
\text { Auditory } \\
\text { Distractor }\end{array}$ & $\begin{array}{l}\text { Broadband } \\
\text { Auditory } \\
\text { Distractor }\end{array}$ & $\begin{array}{c}\text { Visual } \\
\text { Discrimination }\end{array}$ \\
\hline
\end{tabular}

Figure 1. Selective attention task. $A$, Schematic illustration of the front panel of the operant cage. $\boldsymbol{B}$, Temporal course of the visual discrimination task with auditory distractors presented at an irregular rate. $C$, Twelve day experimental protocol.

diminish habituation to auditory distractors, auditory stimuli were delivered at irregular interstimulus intervals that were centered at $400 \mathrm{~ms}$ $(2.5 \mathrm{~Hz}$ rate) and pseudorandomly ranged between 667 and $286 \mathrm{~ms}$ (1.5-3.5 Hz rate, uniformly distributed intervals; Fig. 1B). Clicks, tones, and BBN were delivered through a tweeter (Realistic super tweeter; Radioshack; frequency response $5-40 \mathrm{kHz}$ ) located $120 \mathrm{~cm}$ above the floor of the operant cage. Sound pressure calibrations inside the operant cage were performed with a $1 / 2$ inch Bruel and Kjaer microphone that revealed $<10 \mathrm{~dB}$ of variation in different positions of the behavioral cage.

The $\mathrm{C}+\mathrm{T}$ compound stimuli consisted of a click and a $15 \mathrm{kHz}$ tone (presented $40 \mathrm{~ms}$ after the click) that were always presented together. These stimuli were chosen to assess a selective attention paradigm similar to that used by Delano et al. (2007) in chinchillas. The $15 \mathrm{kHz}$ tone was selected because there is evidence of a higher density of olivocochlear innervation at this position of the cochlea in mice (Maison et al., 2003). To increase auditory distractibility progressively along the behavioral protocol, the order of presentation of the auditory distractors was designed to be from moderate to high sound pressure levels. Therefore, $\mathrm{C}+\mathrm{T}$ stimuli at $\sim 65 \mathrm{~dB}$ SPL were presented during days $4-6$ and the BBN at $\sim 90 \mathrm{~dB}$ SPL was presented during days 7-9.

Open-field measurements. To measure the locomotor activity of mice before the experimental protocol, a group of $10 \mathrm{WT}$ and nine $\alpha 9-\mathrm{KO}$ mice were evaluated in an open-field apparatus. The apparatus was an acrylic box of $40 \mathrm{~cm}$ length $\times 40 \mathrm{~cm}$ width $\times 22 \mathrm{~cm}$ height with a luminous intensity of 40 lux (Prut and Belzung, 2003). Each mouse was placed in the center of the open-field apparatus and was allowed to explore for $5 \mathrm{~min}$. The spontaneous locomotor activity was monitored with a digital video camera. Data were stored and analyzed offline by a researcher blinded to the genotype of mice using the software ANY-maze $\mathrm{v} 4.70$ (Stoelting). The analyzed variables were as follows: total distance, number of center entries, and time spent at the center.

Electrophysiological procedures. All electrophysiological procedures were conducted by one experimenter blinded to the genotype of the animals and were performed in a soundproof chamber after the behavioral protocol was completed. The electrophysiological recordings were performed in $16 \mathrm{KO}$ mice and in $13 \mathrm{WT}$ mice because two WT mice and one $\mathrm{KO}$ mouse died before assessing the electrophysiological evaluation. To perform recordings, all mice were anesthetized with xylazine (10 $\mathrm{mg} / \mathrm{kg}, \mathrm{IP})$ and ketamine $(100 \mathrm{mg} / \mathrm{kg}$, IP) and body temperature was maintained at $37-38^{\circ} \mathrm{C}$ by means of a heating pad.

Two different measures were obtained from auditory brainstem responses (ABR) to ipsilateral $15 \mathrm{kHz}$ tone bursts: (1) wave V ABR thresholds (using different sound pressure levels, from 0-90 dB SPL) and (2) contralateral BBN suppression of wave I obtained with $15 \mathrm{kHz}$ ABR at 80 $\mathrm{dB}$ SPL. Wave V was chosen to obtain auditory thresholds because it is the most constant response to auditory stimuli; wave I was chosen in the contralateral noise evaluation as a measure of the suppressive strength of the olivocochlear reflex in auditory nerve responses (Lichtenhan et al., 2016).

The auditory stimuli used in the estimation of ABR thresholds and in contralateral suppression of wave I were as follows: (1) ipsilateral (right) $15 \mathrm{kHz}$ tone bursts of alternating polarity ( $5 \mathrm{~ms}$ duration, $0.5 \mathrm{~ms}$ rise/fall time) delivered at different sound pressure levels and (2) contralateral (left) BBN (5-40 kHz), $200 \mathrm{~ms}$, delivered at $60 \mathrm{~dB}$ SPL. Tone bursts and broad band noise were presented at $4 \mathrm{~Hz}$ rate and were digitally generated by two synchronized National Instruments PCI boards (6071-E) at 100,000 samples/s, attenuated by PA-5 programmable attenuators (Tucker Davis Technologies system III) and were delivered with two tweeters (one for ipsilateral and the second for contralateral auditory stimuli; Realistic super tweeter; Radioshack; frequency response 5-40 $\mathrm{kHz}$ ) through tubes sealed to the external auditory meatus.

ABR signals were acquired with a technique similar to that described by Melki et al. (2014). Two subdermal needle electrodes were inserted percutaneously to the left and right ear canal in direction to the round window and a third electrode was located in the midline of the animal cranium. The electrophysiological signals were amplified $10,000-100,000 \times$ and filtered between 0.3 and $3 \mathrm{kHz}$ using a BMA200 differential preamplifier (CWE) and a second stage filter (KrohnHite, model 3323). Signals were acquired and digitized at 40,000 samples/s with a National Instruments board (6071-E). Evoked po- 

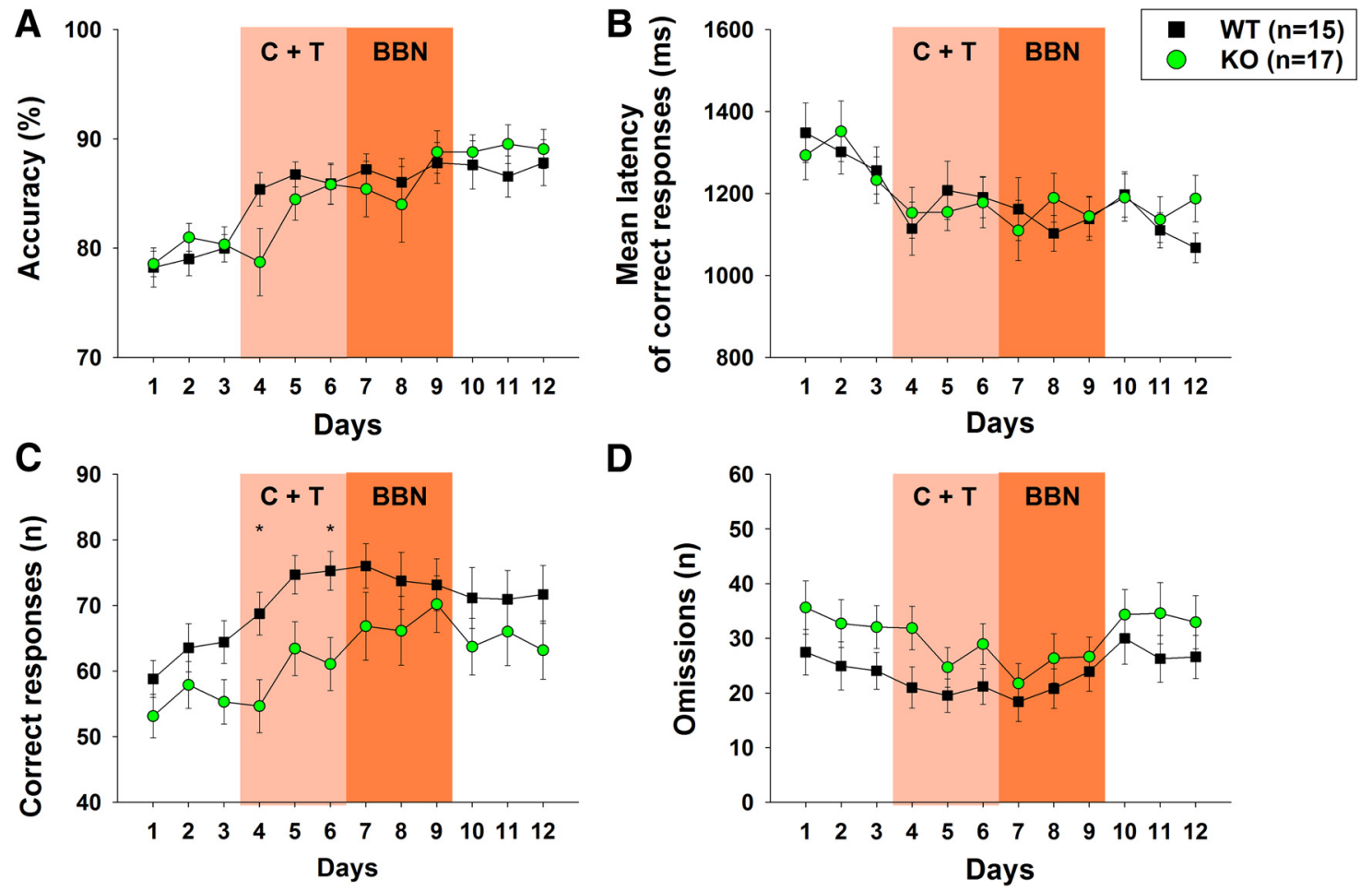

D

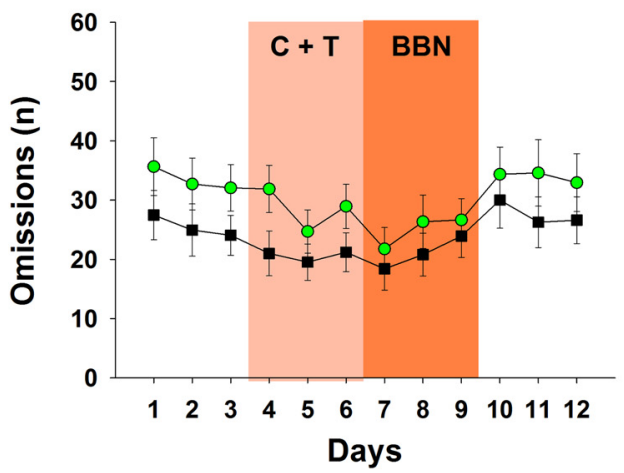

Figure 2. Behavioral performance of WT and $\alpha 9$-nAChR KO mice in the 12-days experimental protocol. A, Accuracy increases in a parallel manner in K0 and WT mice along days and, although there is a tendency in $\mathrm{KO}$ mice to have less accuracy in the fourth day of the protocol (first day of $\mathrm{C}+\mathrm{T}$ period), no significant differences were found. $\boldsymbol{B}$, Mean latency of correct responses diminished along days in similar manner in WT and KO mice. C, There are significant reductions in the number of correct responses in $\mathrm{KO}$ mice during the presentation of the $C+\mathrm{T}$ distractor in the fourth and sixth day of the behavioral protocol. $\boldsymbol{D}$, In addition, although there was a tendency to have more omitted trials during the $\mathrm{C}+$ T period in $\mathrm{KO}$ mice, no significant effects were obtained in this analysis $\left({ }^{*} p<\right.$ 0.05 ; all variables are plotted as mean $\pm \mathrm{SEM})$.

tentials (ABR waves I and V) amplitudes were obtained by averaging 512 trials with and without contralateral noise using a custom-made C program (LabWindows). ABR thresholds were defined as the lowest tone intensity ( $\mathrm{dB}$ SPL) that evokes an averaged response evaluated by visual inspection of ABR waveforms by an expert observer. ABR amplitudes were calculated using a peak to peak method. Amplitude suppression of ABR wave I produced by contralateral noise in WT and $\mathrm{KO}$ mice were calculated in $\mathrm{dB}$ referenced to wave I amplitude without contralateral noise: $\left(\mathrm{dB}_{\text {amplitude suppression }}=20 * \log _{10}\right.$ [wave I amplitude with noise/wave I amplitude without noise]).

Statistical analyses. Because mice were evaluated during different months, before data pooling, the effect of different time assessment (months) was evaluated using Kruskal-Wallis one-way ANOVA. The effects of time assessment of experiments was not significant for any measured variable. Shapiro-Wilk tests were performed to evaluate the distribution of data. In the cases of normal distributed data, two-way repeated-measures ANOVA (RM-ANOVA) was used to analyze differences between days [genotypes: $(\mathrm{WT}, \mathrm{KO}) \times$ days $(1-12)]$ periods [genotypes: $(\mathrm{WT}, \mathrm{KO}) \times$ period $(\mathrm{PRE}, \mathrm{C}+\mathrm{T}, \mathrm{BBN}, \mathrm{POST})]$ or blocks along sessions [genotypes $(\mathrm{WT}, \mathrm{KO}) \times$ blocks $(1,2,3,4,5)$ ]. Non-normal distributed data were transformed to $[\log (X+1)]$ to satisfy requirements of the ANOVA model. All statistical analyses were followed by Bonferroni post hoc comparison tests.

In addition, to measure the day-to-day variability of accuracy, correct, and omitted trials along the experimental protocol, we calculated the individual differences of these variables produced in consecutive days in WT and KO mice (e.g., accuracy in day 2 minus day 1; day 3 minus day 2; up to day 12 minus day 11). These analyses yielded 11 differential values per genotype per variable that were evaluated with a bootstrapped routine with 1000 iterations using the $\mathrm{R}$ programming language ( $\mathrm{R}$ version 3.2.5; R Core Team, 2014). This procedure allowed us to obtain the median, interquartile range, and $95 \%$ confidence interval (CI) of these variables.
Fisher's exact tests were used to compare the distributions of $\mathrm{KO}$ and WT mice with the two arbitrary behavioral criteria. Spearman correlation tests were used to evaluate possible correlations between variables. Multivariate logistic regressions were calculated for modeling data, using forward and backward methods to isolate significant variables. ABR wave $\mathrm{V}$ thresholds and the magnitude of contralateral noise suppression of wave I between $\mathrm{WT}$ and KO mice were evaluated by unpaired $t$ tests. A $p$-value $<0.05$ was considered a significant difference in all statistical tests.

\section{Results}

A summary of the behavioral performance evaluated for the $12 \mathrm{~d}$ of the experimental protocol, including $17 \mathrm{KO}$ and $15 \mathrm{WT}$ mice, is shown in Figure 2. No accuracy differences between $\mathrm{KO}$ and WT mice were obtained in the first $3 \mathrm{~d}$ of protocol (visual discrimination without auditory distractors). After that, a significant progressive increase along days in accuracy (two-way RM-ANOVA, $\left.F_{(1,11)}=10.846 ; p<0.001\right)$ and decrease in the latency of correct responses along days were found in both genotypes (Fig. $2 A, B$ ). The post hoc analysis of the daily performance along the $12 \mathrm{~d}$ protocol showed a trend toward a differential effect in accuracy between genotypes in day 4 ; that is, in the first day of presentation of the $\mathrm{C}+\mathrm{T}$ distractors (Bonferroni post hoc test, $t=$ $1.89, p=0.06)$. Significant differences in the number of correct responses between $\mathrm{KO}$ and WT mice were obtained comparing daily performance (two-way RM-ANOVA, $F_{(1,11)}=3.066 ; p<$ $0.001)$. The Bonferroni post hoc test showed that these differences were statistically significant in days 4 and 6 of the protocol during the presentation of $\mathrm{C}+\mathrm{T}$ distractors for correct responses (day 4 $\mathrm{WT}=68.73 \pm 12.71$ mean $\pm \mathrm{SD} ; \mathrm{KO}=54.64 \pm 17.18$; day 6 $\mathrm{WT}=75.27 \pm 11.39 ; \mathrm{KO}=61.05 \pm 17.15$; Fig. $2 C)$, whereas a 
A

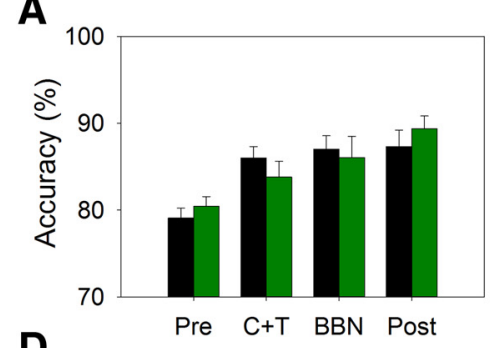

D

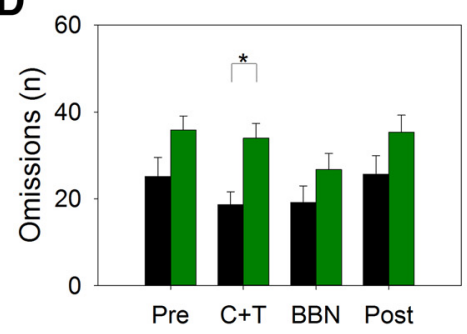

B

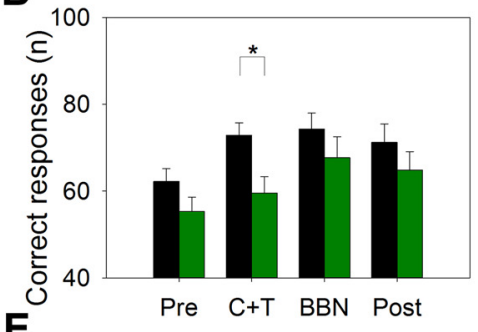

E

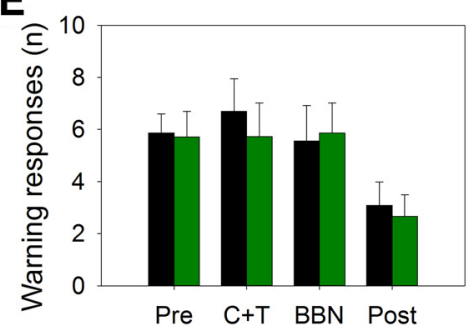

C
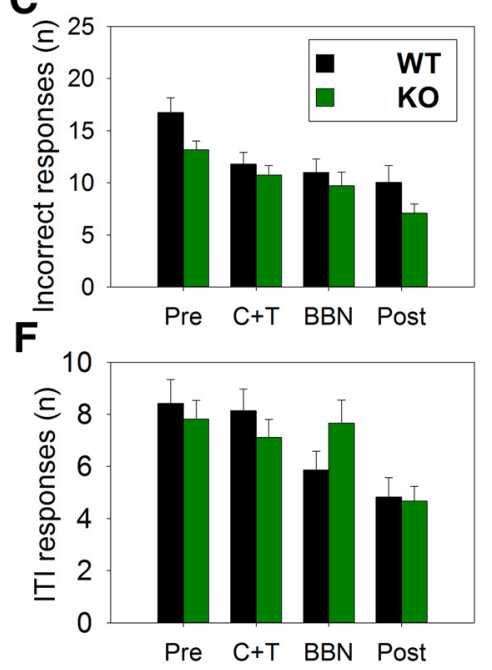

Figure 3. Behavioral performance ofWT and KO mice in the four periods of the behavioral protocol. A summary of different behavioral measures are shown in green and black bars (mean \pm SEM) for KO and WT mice correspondingly: accuracy $(\boldsymbol{A})$, correct responses $(\boldsymbol{B})$, incorrect responses $(\boldsymbol{C})$, omissions $(\boldsymbol{D})$, warning responses (responses to the central light; $\boldsymbol{E})$, and ITI responses $(\boldsymbol{F})$. Notice that, although statistically significant differences were only obtained during the period with $C+\mathrm{T}$ distractors for correct responses and omitted trials $\left({ }^{*} p<0.05\right)$, the baseline omission difference was almost statistically significant $(p=0.05)$.

tendency was obtained in day $5(\mathrm{WT}=74.67 \pm 11.32 ; \mathrm{KO}=$ $63.41 \pm 17.34 ; p=0.055)$. No significant differences were obtained for omitted trials during the $12 \mathrm{~d}$ analysis (two-way RM ANOVA, $\left.F_{(1,11)}=1.650 ; p=0.083\right)$. Regarding other behavioral variables, there were no significant differences between the number of incorrect, warning and ITI responses, and mice weight between WT and KO mice along the protocol (data not shown).

Next, we analyzed the behavioral performances comparing the four periods of the experimental protocol, including baseline (PRE), C+T, BBN, and POST periods (Fig. 3). Two-way repeated-measures ANOVAs followed by Bonferroni post hoc tests showed that, during the period of presentation of the $\mathrm{C}+\mathrm{T}$ distractors, there was a significant decrease in the number of correct responses in $\mathrm{KO}$ mice $\left(F_{(1,3)}=14.950, p<0.001\right.$; WT $=$ $72.89 \pm 11.04 ; \mathrm{KO}=59.55 \pm 15.71$; Fig. $3 B)$ and a significant increase in the number of omitted trials in $\mathrm{KO}$ mice $\left(F_{(1,3)}=6.70\right.$, $p<0.001 ; \mathrm{WT}=18.62 \pm 11.58 ; \mathrm{KO}=33.98 \pm 14.04$; Fig. $3 D)$. Conversely, whereas there were no significant differences in the number of correct responses and omitted trials during BBN and POST periods between KO and WT mice, there was a difference tendency between genotypes in the number of omission trials during the PRE period (Bonferroni post hoc test, $t=2.015, p=$ $0.05)$. In addition, there were no significant differences between $\mathrm{KO}$ and WT in other behavioral variables, including accuracy and warning, incorrect, and ITI responses (Fig. $3 A, C, E, F$ ). Together, the day-by-day- (Fig. 2) and the period (Fig. 3)-based analyses showed that the number of omitted trials and correct responses during the $\mathrm{C}+\mathrm{T}$ distractor period were the only behavioral variables that were significantly different between KO and WT mice. However, we also found strong tendencies for behavioral differences between $\mathrm{KO}$ and WT mice in the number of omission trials during baseline (PRE) and in accuracy during experimental day 4 $(\mathrm{C}+\mathrm{T})$.

To study whether the behavioral differences in accuracy, correct, and omitted responses between WT and KO mice were produced by the introduction of the auditory distractors, we used a measure of the individual daily change in accuracy, correct, and omitted responses produced during 2 consecutive days of the experimental protocol. These behavioral differences allowed us to study whether the baseline day-to-day variability (e.g., day 2 minus day 1, day 3 minus day 2) was different from that with auditory distractors (e.g., day 4 minus day 3, day 5 minus day 4). Figure 4 shows that the magnitudes of the interquartile ranges (IQRs) for accuracy, omission, and correct day-to-day differences increase during the $\mathrm{C}+\mathrm{T}$ period in $\mathrm{KO}$ mice (differences between day 4 and 3 and day 5 and 4). The bootstrap analysis showed that the $95 \%$ CI of the upper values of the IQR of the accuracy difference between WT and KO mice between days 5 and 4 did not overlap: WT: median 3.0 (95\% CI: 2.1-6.1); KO: median 12.9 (95\% CI: 7.5-19.5). Conversely, IQR differences in omissions and correct responses were not statistically different. These results show that the introduction of the $\mathrm{C}+\mathrm{T}$ distractor generates a behavioral change in the visual discrimination accuracy of $\alpha 9$-nAChR-KO mice.

Subsequently, we developed two behavioral criteria based on the variables that showed significant differences or strong tendencies between genotypes in the previous analyses. These criteria allowed us to separate individuals from WT and KO genotypes. The first criterion was based on the daily number of correct and omitted trials: $<55$ correct responses or $>36$ omitted trials in daily sessions. Nine of $17 \mathrm{KO}$ and two of $15 \mathrm{WT}$ mice complied with this criterion during the $\mathrm{C}+\mathrm{T}$ period (Fig. 5). This differential distribution between KO and WT mice was only significant during the $\mathrm{C}+\mathrm{T}$ period (Fisher's exact test, $p=0.028$ ) because there were no significant differences in the other 3 periods (PRE, Fisher's exact test, $p=0.308$; BBN, Fisher's exact test, $p=0.265$; and POST, Fisher's exact test, $p=0.147$, Fig. $5 A, C, D)$. To identify the subset of WT and KO mice with poor behavior in the PRE period, in Figure 5, these animals are plotted with red border symbols. Figure 5 shows that those animals classified as bad performers in the PRE period are not necessarily the same individuals with altered behavior in the $\mathrm{C}+\mathrm{T}$ period.

The second criterion was based on accuracy in day $4(<77 \%)$ and was developed to detect changes in the behavioral performance between the baseline period and the first day of presentation of the $\mathrm{C}+\mathrm{T}$ distractors. Figure 6 shows individual accuracy plotted against omitted and correct trials in the first $4 \mathrm{~d}$ of the behavioral protocol. Bad KO performers according to the first 
A
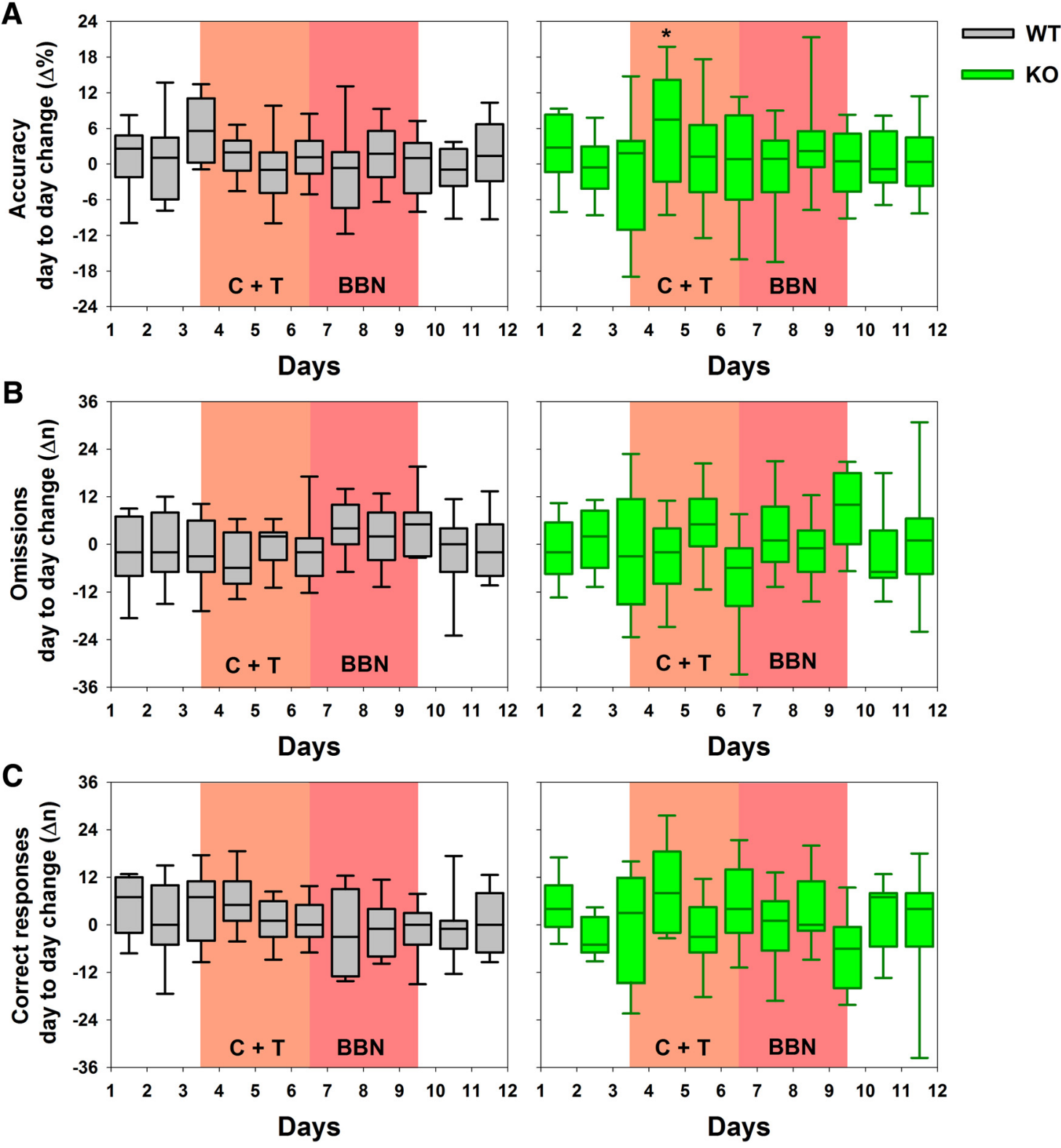

Figure 4. C C T distractors induce changes in the day-to-day behavioral variability in KO mice. Genotype individual differences in consecutive days of the experimental protocol are illustrated as gray and green box plots for WT and KO mice, respectively (which show medians as the horizontal middle line and the first and third quartiles as the limits of the colored areas). Because box plots represent the change in behavioral performance between $2 \mathrm{~d}$, these are plotted between days in the $x$-axis. $A$, Accuracy differences between consecutive days were uniformly distributed in WT mice, whereas a significant change in the upper limit of the IQR in the difference between days 5 and 4 was observed for K0 mice $\left(^{*}\right)$ after the introduction of the $C+T$ distractors. $B, C, A l t h o u g h$ the IQR of the day-to-day differences between omissions and correct responses in $\mathrm{KO}$ mice were larger between days 4 and 3, the $95 \% \mathrm{Cl}$ of these values were not different from the WT $95 \% \mathrm{Cl}$ as assessed by a bootstrapped routine. Notice that the variability was similar in the three variables during the baseline period in both genotypes.

criterion are identified with yellow symbols. According to this second criterion, there was a significant number of $\mathrm{KO}$ mice affected by the $\mathrm{C}+\mathrm{T}$ distractor (eight $\mathrm{KO}$ mice and only one WT mouse, identified by the symbols below the dotted lines during day 4 in Fig. 6, Fisher's exact test, $p=0.018$ ). Moreover, as evident from the figure, bad KO performers according to this second criterion are not necessarily the same individuals as those identified by the first criterion. Taking both behavioral criteria together, we were able to identify 13 of $17 \mathrm{KO}$ mice. Only four KO mice were indistinguishable from WT mice (four green symbols with a black cross in Fig. 6).

Next, we built a multivariate logistic regression model using genotype as the dependent variable ( $\mathrm{WT}=0$ and $\mathrm{KO}=1$ ) and the number of correct and omitted trials during the $\mathrm{C}+\mathrm{T}$ period and accuracy during day 4 as the 3 independent variables. Forward and backward stepwise methods show that the number of correct responses could be removed from the model because they covary with the number of omissions. The independent variables included in the final model were accuracy during day 4 and the number of omissions during the $\mathrm{C}+\mathrm{T}$ period. This analysis yielded a significant behavioral model to predict genotype (logit $p=7.175-(0.117 *$ accuracy day 4$)+(0.107 *$ omissions $)$, likelihood ratio test, $p<0.001$; accuracy day 4, 95\% CI: $0.89-$ $1.02, p=0.083$; omissions, $95 \%$ CI: $1.03-1.11, p=0.01)$. Using this multivariate logistic regression model to predict the genotype of mice during the $\mathrm{C}+\mathrm{T}$ period, we were able to identify 14 of 17 $\mathrm{KO}$ mice. These $14 \mathrm{KO}$ mice included the 13 mice identified by the two previous behavioral criteria. 
A

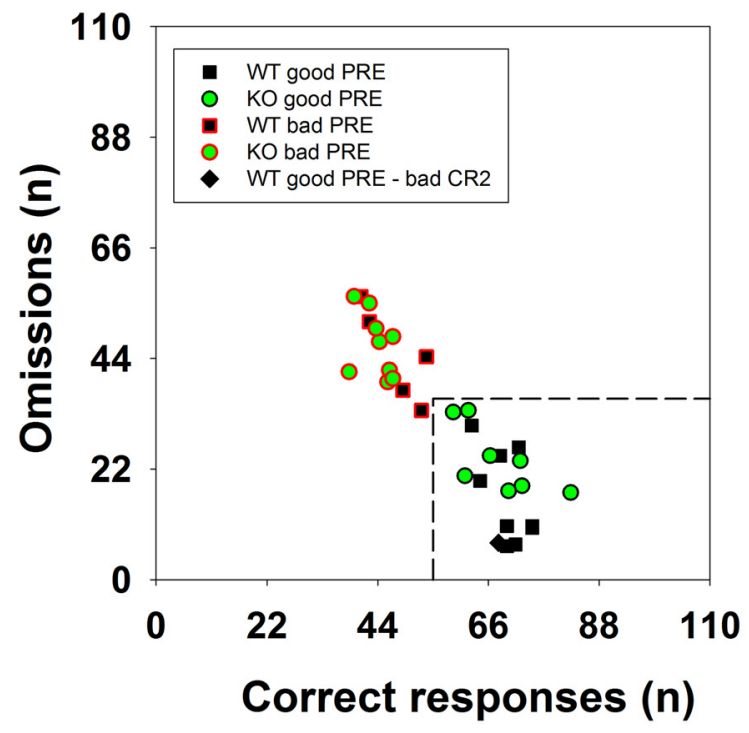

B $\quad$ C + T

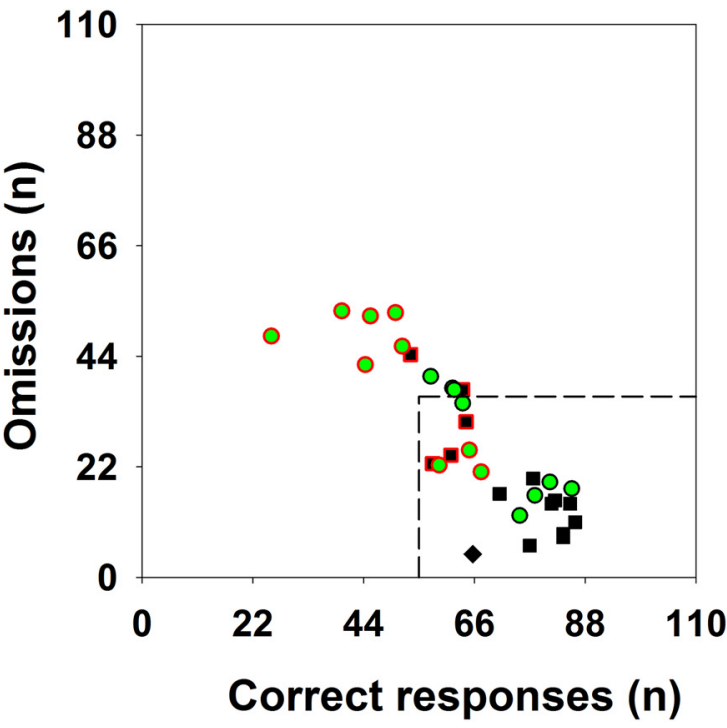

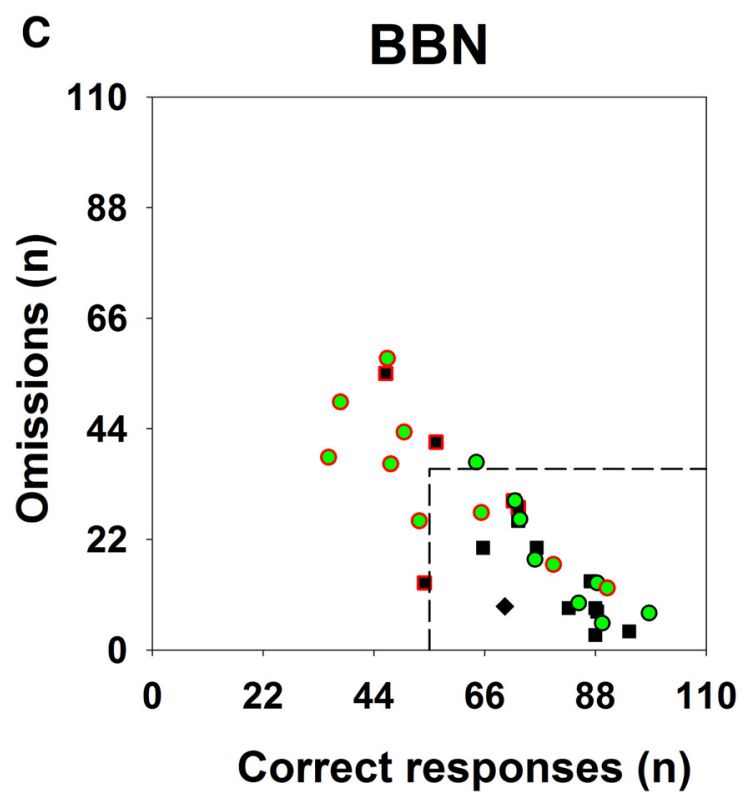

D

POST

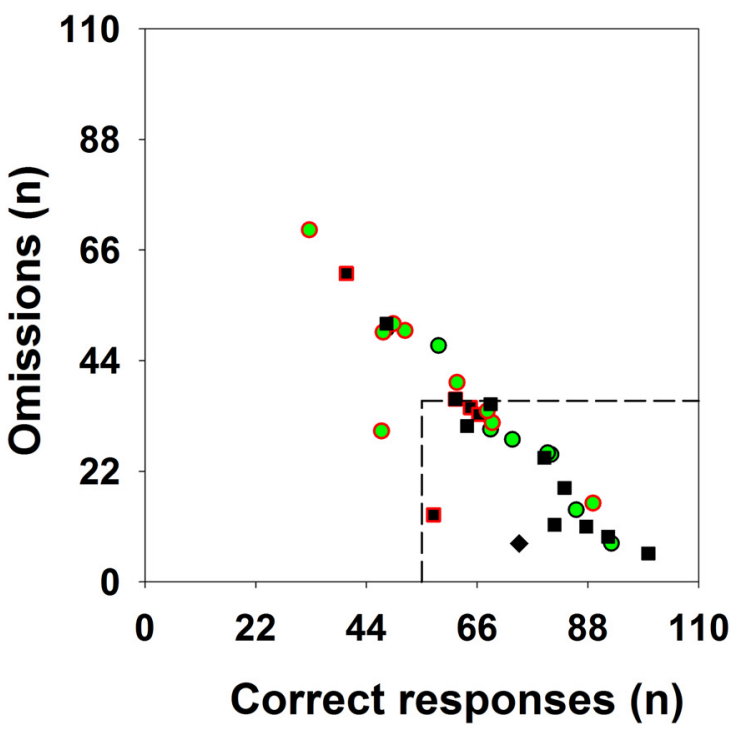

Figure 5. Two different groups of $\mathrm{KO}$ mice can be classified according to the individual behavioral performance with correct and omitted trials during the experimental protocol. The four panels show scatter plots of the number of correct responses (x-axes) and omitted trials (y-axes) for all KO $(n=17)$ and WT $(n=15)$ mice in the four periods of the behavioral protocol. Each symbol represents the behavioral performance of one animal in the corresponding period of the experimental protocol. $A$, visual discrimination only (PRE). $\boldsymbol{B}$, Visual discrimination with $C+T$ distractors. $C$, Visual discrimination with BBN distractor. D, Visual discrimination only (POST). Segmented lines represent the arbitrary behavioral criterion 1 used to classify K0 mice into those with altered behavior ( $<55$ correct responses or $>36$ omitted trials) from those with compensated behavior (similar to WT mice). The symbols with red borders represent the subset of WT and K0 mice with altered behavior in the PRE period. The black diamond symbol represents one WT mouse with bad behavior according to behavioral criterion 2 (CR2, see Fig. 6), which is a good performer in the PRE period. The performance of these animals can be followed in the other three periods of the experimental protocol. Notice that there are three KO mice with altered behavior during the PRE period that are good performers in the other periods of the experimental protocol.

Although the main differences found between WT and KO mice were obtained during the $\mathrm{C}+\mathrm{T}$ distractor period, there was a tendency in $\mathrm{KO}$ mice to have more omitted trials during the baseline period. For that reason, we evaluated the locomotor activity and anxiety-like behavior in another group of nine $\alpha 9-\mathrm{KO}$ and 10 WT mice using the open-field test before the experimental protocol (Prut and Belzung, 2003). There were no significant differences in the total distance traveled, the number of center entries, or the time spent in the center between WT and KO mice (Fig. 7). These results indicate that the deletion of $\alpha 9-\mathrm{nAChR}$ does not affect the basal locomotor activity and suggest no anxi- ety differences between genotypes. Therefore, any possible difference tendency in the baseline number of omitted responses between WT and $\mathrm{KO}$ mice is not due to differences in locomotor activity at the start of the experimental protocol.

To evaluate whether the individual variability of the olivocochlear reflex strength in WT and KO mice could explain the behavioral results, we measured amplitude suppression of ABRwave I by contralateral BBN stimulation. This brainstem reflex is a widely used method to evaluate olivocochlear activity on auditory nerve responses (ABR wave I; Lichtenhan et al., 2016). In addition, we evaluated auditory thresholds by measuring ABR 

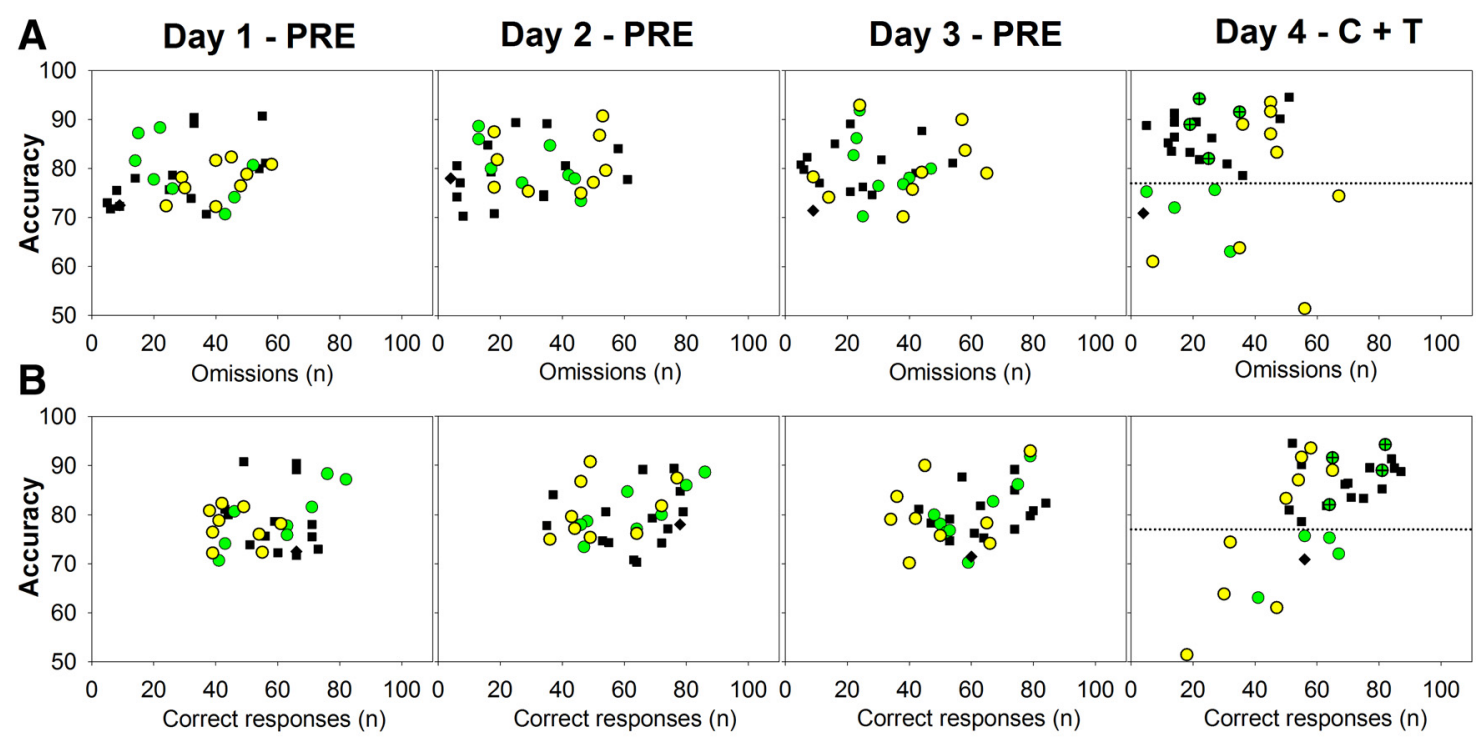

$\begin{array}{ll}- & \text { WT } \\ \circ & \text { KO good CR1 } \\ \circ & \text { KO bad CR1 } \\ \oplus & \text { KO compensated } \\ \bullet & \text { WT bad CR2 }\end{array}$

Figure 6. Accuracy change between predistractor and $C+$ T period in KO mice. $A$, The four panels show scatter plots of the number of omitted trials $(x$-axes) and accuracy $(y$-axes) for all $K 0(n=$ 17) and WT ( $n=15)$ mice in the first $4 \mathrm{~d}$ of the behavioral protocol. The yellow and green symbols represent the subsets of KO mice with altered (KO bad CR1) and compensated behavior (KO good CR1) according to the first criterion during the C + T period. $\boldsymbol{B}$, Number of correct responses (x-axes) and accuracy (y-axes) for all KO $(n=17)$ and WT $(n=15)$ mice in the first $4 \mathrm{~d}$ of the behavioral protocol. Notice that, according to accuracy, during the first $3 \mathrm{~d}$ of the experimental protocol (PRE), KO and WT mice cannot be separated, but a significant separation of groups can be performed during day 4 (first day with C + T distractors). Using the second criterion of $<77 \%$ accuracy (dotted lines), we can identify eight $K 0$ mice and only one WT mouse shown with black diamond symbols (Fisher's exact test, $p=0.018$ ). Green symbols with a cross inside represent $\mathrm{KO}$ mice with compensated behavior in both criteria (K0 compensated).
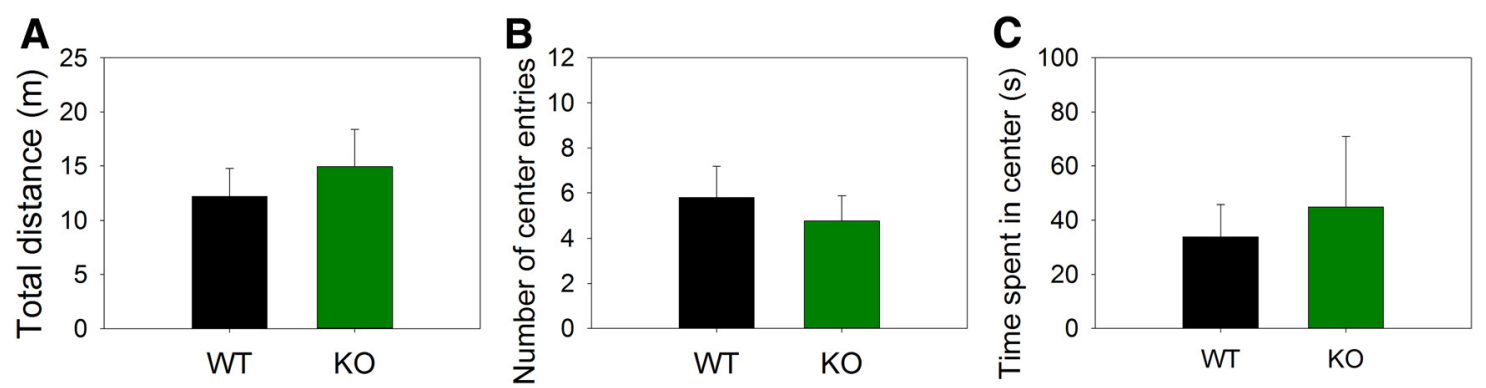

Figure 7. There is no difference in motor activity between WT and KO mice. Locomotor activity was evaluated using an open-field test in WT $(n=10)$ and KO $(n=9)$ mice. Nonsignificant differences between genotypes were obtained. $\boldsymbol{A}$, Total distance. $\boldsymbol{B}$, Number of center entries. $\boldsymbol{C}$, Time spent in center. Data are shown as mean \pm SEM.

wave $\mathrm{V}$ to $15 \mathrm{kHz}$ tone bursts. Figure $8, A$ and $B$, shows that, whereas there were no differences in ABR thresholds to $15 \mathrm{kHz}$ tones between WT $(32.1 \pm 1.9 \mathrm{~dB}$ SPL $)$ and $\mathrm{KO}(31.8 \pm 1.3 \mathrm{~dB}$ SPL) mice, a significant difference (unpaired $t$ test, $t_{(27)}=13.98$, $p<0.001)$ was obtained in the magnitude of contralateral noise suppression of wave I (WT: $2.99 \pm 0.40 \mathrm{~dB}$ amplitude suppression, KO: $0.83 \pm 0.43 \mathrm{~dB}$ amplitude suppression). We also compared wave I suppression for 2 subsets of $\mathrm{KO}$ mice using the behavioral criterion 1 ( $<55$ correct responses and $>36$ omitted trials during the $\mathrm{C}+\mathrm{T}$ period) and found no differences between altered $(n=9)$ and compensated $(n=8) \mathrm{KO}$ mice (Fig. $8 C$ ). Finally, we correlated single-day performance of WT and KO mice considering the number of correct responses and omitted trials in the $\mathrm{C}+\mathrm{T}$ period and accuracy in day 4 of the behavioral protocol with the individual magnitude of contralateral noise suppression of wave I (Fig. $8 D, E, F$ ). The effects of contralateral noise suppression of wave I in WT and KO mice were analyzed together $(n=29)$ and significant positive and negative correla- tions between the magnitude of contralateral noise suppression of wave I and the number of correct responses (Spearman $r_{(29)}=$ 0.407, $p=0.0286$ ) and omitted trials (Spearman $r_{(29)}=-0.556$, $p=0.00186)$ during the period of $\mathrm{C}+\mathrm{T}$ distractors were found. However, there were no significant correlations analyzing each genotype alone. In addition, no significant correlations were found for accuracy in day 4 and wave I suppression (Fig. $8 F$ ).

To test whether correct responses and omitted trials changed along daily sessions, we divided the behavioral performance into five blocks of 22 trials for each day (each daily session is comprised of 110 trials; Fig. 9). This analysis allowed us to study a possible differential decrement of sustained attention to visual stimuli between WT and KO mice. A two-way RM- ANOVA was performed for days 4-6 because these days showed significant differences in the previous analyses. Significant effects of genotype and blocks were obtained for the number of correct responses along sessions for day $4\left(F_{(1,4)}=2.46, p=0.048\right)$ and a Bonferroni post hoc test showed significant differences in correct 
A

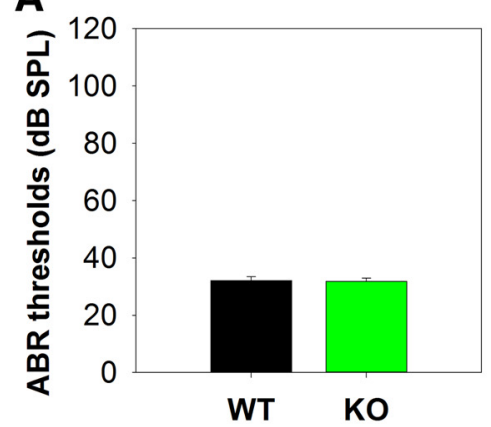

D

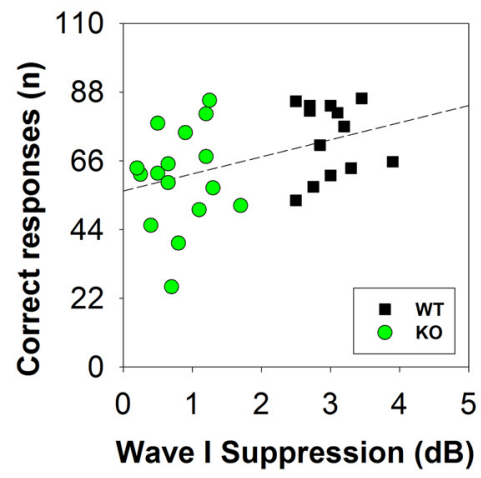

B

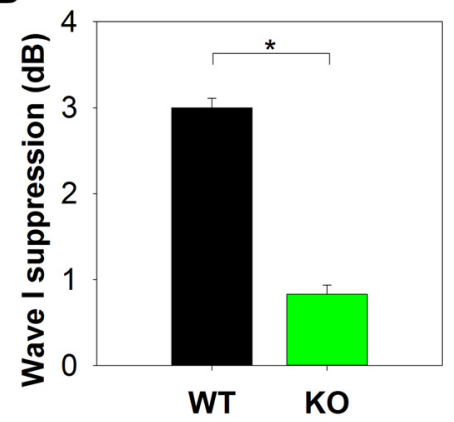

E

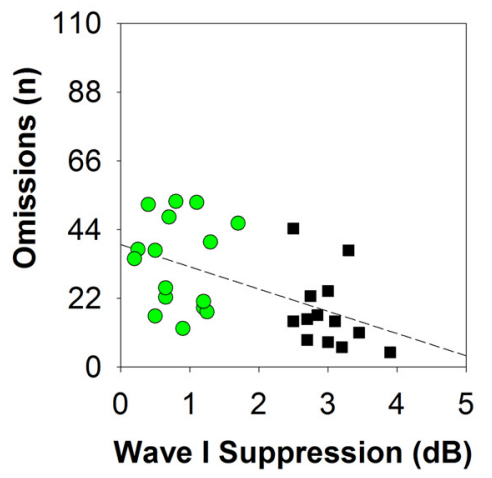

C

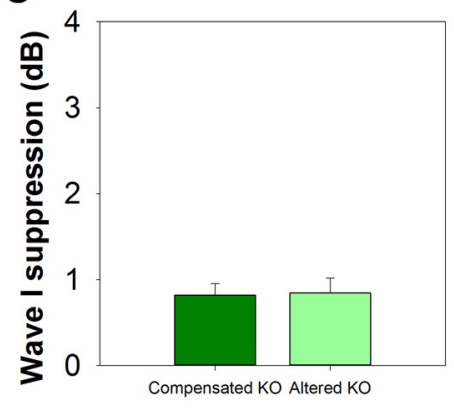

$\mathbf{F}$

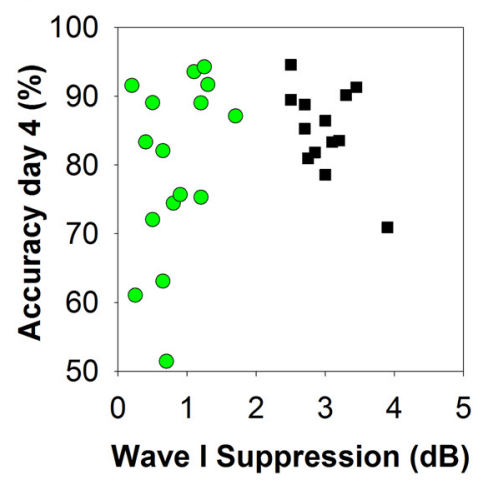

Figure 8. ABR thresholds and suppression of wave I with contralateral noise in WT and K0 mice. $A$, There were no significant differences in ABR thresholds for $15 \mathrm{kHz}$ stimulus between WT and KO mice. $\boldsymbol{B}$, Contralateral noise suppression of wave I was significantly larger for WT mice than for KO mice. $\boldsymbol{C}$, There were no significant differences in the magnitude of contralateral suppression of wave I between the two groups of KO (altered and compensated behavior according to criterion 1). $\boldsymbol{A}-\boldsymbol{C}$, Mean \pm SEM. $\boldsymbol{D}$, Taking both genotypes together, there was a significant positive correlation between contralateral noise suppression of wave I and the number of correct responses during the period of $C+\mathrm{T}$ distractors (Spearman $r_{(29)}=0.407, p=0.029$, linear regression equation: $y=56.347+5.4597 x)$, however, no significant correlations were obtained analyzing each genotype alone. $\boldsymbol{E}$, Analyzing all animals from both genotypes, a significant negative correlation between the magnitude of contralateral noise suppression of wave I and omitted trials was obtained (Spearman $r_{(29)}=-0.556, p=0.002$, linear regression equation: $y=39.1554-7.1102 x$ ). However, no significant correlations were obtained analyzing each genotype alone. $\boldsymbol{F}$, There were no significant correlations between accuracy in day 4 and contralateral noise suppression of wave I.

responses between genotypes for the 2 first blocks (trials 1-44) of day 4 (Fig. 9A). Omitted trials had significant effects for genotype and blocks in day $4\left(F_{(1,4)}=4.066 ; p<0.05\right)$ and for genotype in day $6\left(F_{(1,150)}=7208, p<0.05\right)$. Bonferroni post hoc analyses showed differences between genotype for the first 66 trials in day 4 and for the last 44 trials in day 6 (Fig. 9B). Figure 9, $C$ and $D$, shows the distribution of individual mice performance sorted by correct responses and omissions in the first 22 trials of day 4 (Fig. $8 C$ ) and in the last 22 trials of day 6 (Fig. 9D). Considering a behavioral criterion of $50 \%$ of the correct responses ( $\leq 11$ correct responses, for 22 trials), we found that $\mathrm{KO}$ and WT mice have different distributions in the first 22 trials of day 4 (Fisher's exact test, $p=0.018$ ) and in the last trials of day 6 (Fisher's exact test, $p=0.028)$. In this figure, bad KO performers in the first 22 trials of day 4 are identified with red border symbols, showing that $\mathrm{KO}$ mice that were affected in day 4 are not necessarily the same affected in day 6 . These results suggest the presence of two different effects with $\mathrm{C}+\mathrm{T}$ distractors in KO mice: (1) a day 4 effect, which seems to be related to first moment of auditory distraction, and (2) a day 6 effect, which could be related to sustained attention deficits in the $\alpha 9-\mathrm{KO}$ mice.

To determine whether there are genotype differences in sustained attention to visual stimuli with auditory distractors, we analyzed the slope of the regression line fitted to the omissions in the first and last 22 trials of each day during the four periods (PRE, C+T, BBN, POST) of the experimental protocol (Fig. 9B). A two-way RM ANOVA showed no statistically significant differences in the slope of omissions between $\mathrm{KO}$ and WT mice $\left(F_{(1,3)}=1.469, p=0.235 ; \mathrm{WT}_{\text {omission slope }}=0.468 \pm 0.231\right.$
$($ mean $\pm \mathrm{SEM}) ; \mathrm{KO}_{\text {omission slope }}=0.853 \pm 0.217$ ), whereas significant differences were obtained for the slopes in the different periods of the experimental protocol $\left(F_{(1,3)}=5.200, p=0.002\right.$; $\mathrm{PRE}_{\text {omission slope }}=0.421 ; \mathrm{T}+\mathrm{C}_{\text {omission slope }}=0.484 ; \mathrm{BBN}_{\text {omission slope }}$ $=0.835$ POST $\left._{\text {omission slope }}=0.901\right)$. A Bonferroni post hoc test showed significant differences between the POST and the $\mathrm{C}+\mathrm{T}$ and PRE periods. These analyses show no genotype differences in sustained attention to visual stimuli with auditory distractors, but a general effect along days showing that omissions slopes between the first and last blocks of the experimental protocol became steeper in the POST period in both genotypes.

\section{Discussion}

In the present study, we show that $\alpha 9$-nAChR KO mice, which lack cholinergic transmission between MOC and OHC, have worse behavioral performance than WT mice during selective attention to visual stimuli using auditory distractors. These results demonstrate that an intact medial olivocochlear transmission aids in reducing cochlear sensitivity during selective attention to visual stimuli.

Behavioral differences between $\mathrm{KO}$ and WT mice during tone and click distractors

KO mice made significantly fewer correct responses and more omissions during the presentation of the $\mathrm{C}+\mathrm{T}$ distractors at 65 dB SPL. Moreover, KO mice had a significant increased variability range in the day-to-day difference in accuracy during the $\mathrm{C}+\mathrm{T}$ distractor period. These results can be related to our previous work in chinchillas, in which we used a similar behavioral para- 

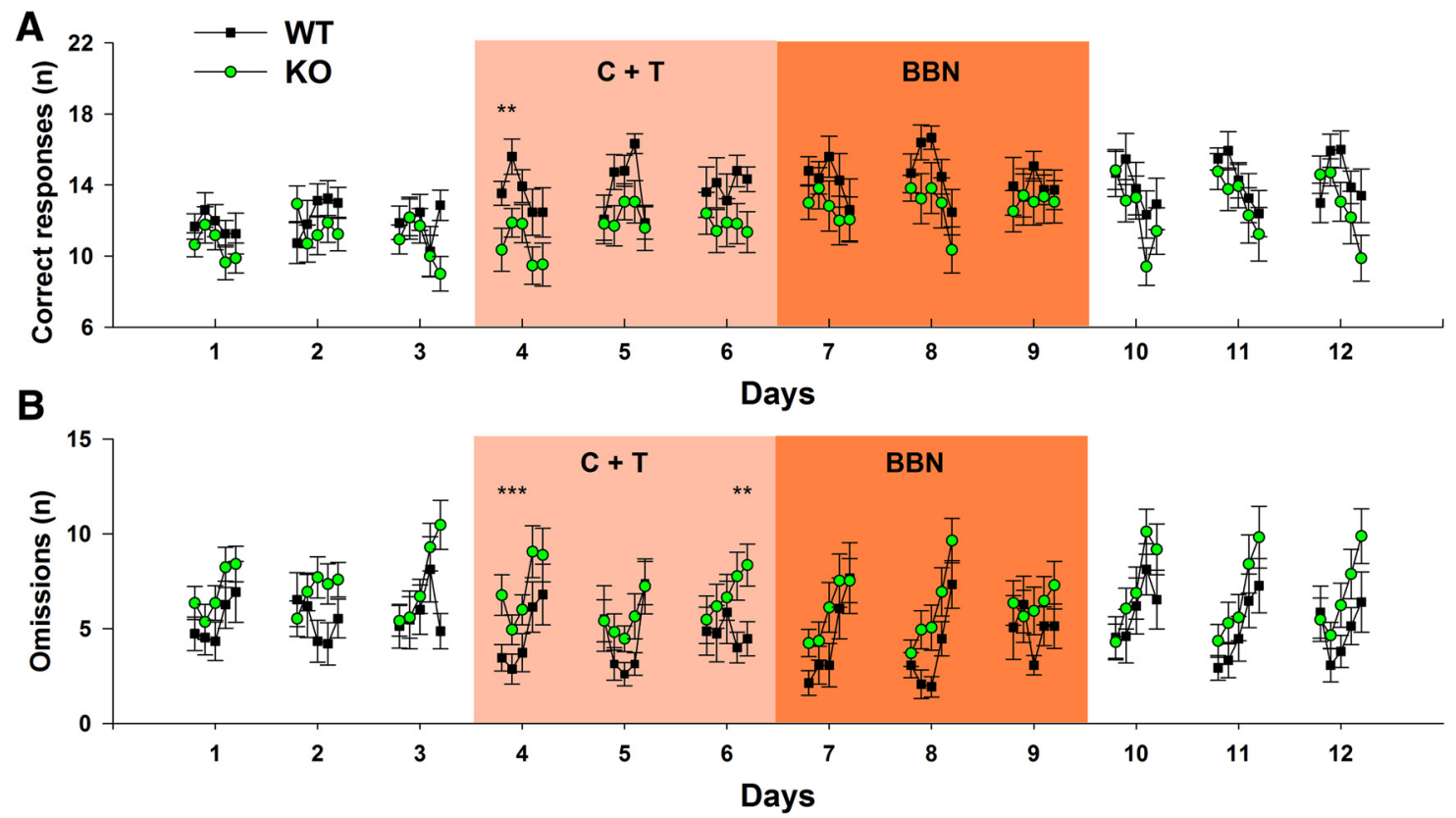

C

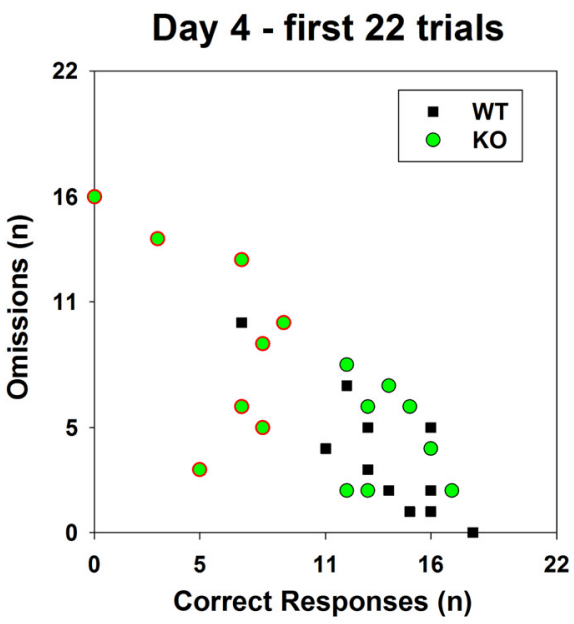

D

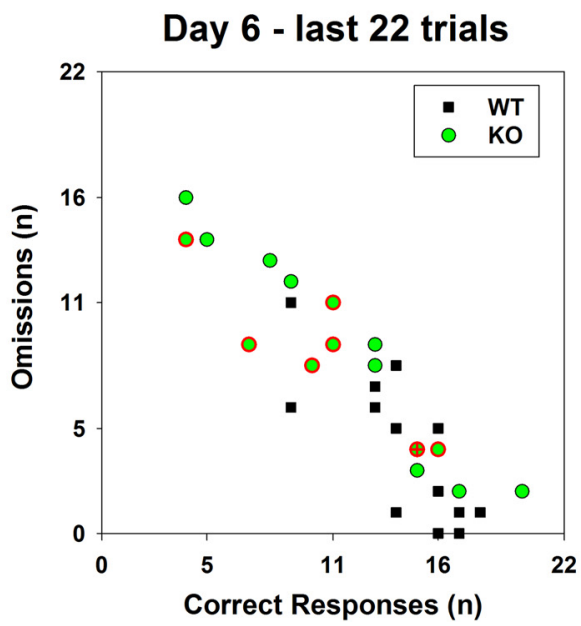

Figure 9. Behavioral differences between WT and K0 mice are produced in the first trials of day 4 and in the last trials of day $6 . A, B$, Number of correct responses and omitted trials in the five blocks of 22 trials along the $12 \mathrm{~d}$ protocol (mean \pm SEM). Notice that the omissions slopes between the first and last blocks of the experimental protocol became steeper in both genotypes along days. $C$, Each point corresponds to the behavioral performance during the first 22 trials of day 4 . In this figure, the symbols with red borders represent the subset of $K 0$ mice with $<12$ correct responses in the first 22 trials of day 4. D, Behavioral performance of the last 22 trials of day 6 , the symbols with red borders are the same $K 0$ animals depicted in $\boldsymbol{C}$. The red crossed $K 0$ symbol represents two animals. Notice that $\mathrm{KO}$ mice affected in day 4 are not necessarily the same as those affected in day 6.

digm to assess selective attention to visual stimuli with $\mathrm{C}+\mathrm{T}$ distractors (Delano et al., 2007). In that study, we found CAP (auditory nerve) amplitude reductions concomitant to CM increases during correct trials, whereas no differences were obtained during omitted trials. These results from chinchilla experiments suggested that MOC would be activated during correct trials, whereas there might be less or no MOC activation during omissions. This was confirmed in the present work because $\alpha 9$-nAChR KO mice, which lack MOC activity (Vetter et al., 1999), indeed have more omitted trials and fewer correct responses with $\mathrm{C}+\mathrm{T}$ distractors.

In addition to the significant effects obtained during the $\mathrm{C}+\mathrm{T}$ period, there was a tendency toward more omissions in the baseline period in $\mathrm{KO}$ mice that was not due to locomotor differences between genotypes (Fig. 7). A speculative explanation to this behavioral tendency is that MOC activity could be also needed to suppress sounds generated by mice during visual discrimination.
Physiological mechanisms of the behavioral differences observed in the $\mathrm{KO}$ mice

Alpha-9 nicotinic receptor subunits assemble with $\alpha 10$ subunits to form the receptor that mediates synaptic transmission between MOC fibers and OHC (Elgoyhen et al., 2001; Vetter et al., 2007). They are also present in type II vestibular hair cells as targets of vestibular efferents (Kong et al., 2006). Other sites of $\alpha 9$ expression include the skin, nasal epithelium, the pars tuberalis of the pituitary gland, human and rat urothelium, human and rat placenta, rat heart, dorsal root ganglia, and a variety of immune cells (for review, see McIntosh et al., 2009). However, as reported by Elgoyhen et al. (1994) and confirmed by searching the Allen Brain Atlas (2012), $\alpha 9$ is not expressed in the brain. Given these expression pattern of the $\alpha 9$ nicotinic subunit, the most likely conclusion is that peripheral responses to auditory distractors during visual attention are filtered through the activation of corticofugal pathways (Leon et al., 2012; Dragicevic et al., 
2015), which in turn recruit MOC neurons that suppress peripheral responses.

\section{Lack of behavioral differences between $\mathrm{KO}$ and WT mice during $\mathrm{BBN}$ distractors}

Although KO mice have altered behavior compared with WT mice during selective attention to visual stimuli in the presence of $\mathrm{C}+\mathrm{T}$ distractors, no differences were obtained when using BBN as a distractor. Because, in our experimental protocol, BBN was presented in the days after the $\mathrm{C}+\mathrm{T}$ period, the lack of behavioral differences in WT and $\mathrm{KO}$ mice could be explained by the fact that adaptive training along days can diminish distractibility (Mishra et al., 2014). Therefore, the behavioral differences observed between WT and KO mice during the $\mathrm{C}+\mathrm{T}$ period could have been compensated for by central mechanisms produced by the behavioral training along days of the experimental protocol. Another possibility to explain the lack of behavioral differences between genotypes during the $\mathrm{BBN}$ period could be the activation of the middle ear reflex (MEM; Borg and Counter, 1989). Evidence obtained in mice shows that the MEM activation threshold with contralateral BBN is $\sim 80 \mathrm{~dB}$ SPL (Valero et al., 2016). Because, in the present study, the sound levels of BBN distractors were $\sim 90 \mathrm{~dB}$ SPL, it is probable that MEMs were active and suppressing BBN distractors during attention to visual stimuli in $\mathrm{WT}$ and $\mathrm{KO}$ mice. However, because the sound pressure of $\mathrm{C}+\mathrm{T}$ distractors were $\sim 65 \mathrm{~dB}$ SPL, it is unlikely that MEM activation contributes to suppression of these acoustic stimuli.

\section{Two populations of KO mice: altered and compensated behavior}

Although we found clear behavioral differences between the groups of WT and KO mice, single-day analyses of the individuals and the multivariate logistic regression analysis revealed the presence of two different populations of $\mathrm{KO}$ mice during selective attention to visual stimuli with auditory distractors: altered and compensated KO. A similar variability was observed by Lauer and May (2011) when evaluating a similar group of $\alpha 9$-nAChR KO mice in a behavioral task designed to measure auditory temporal acuity (gap-induced inhibition of the acoustic startle reflex). These investigators found two groups of $\mathrm{KO}$ mice, one with altered temporal auditory responses and a second with compensated responses similar to that of their WT mice. Therefore, both behavioral studies show that, at least in a subset of $\alpha 9$-nAChR KO mice, compensatory mechanisms are sufficient to reverse the behavioral deficits.

A possible explanation for the behavioral compensation observed in a fraction of $\mathrm{KO}$ mice may derive from attention mechanisms needed to suppress irrelevant stimuli involving corticocortical or corticostriatal networks (Aboitiz et al., 2014) and not from lower brainstem pathways. The fact that we did not find any $\mathrm{KO}$ mice that compensated for the $\mathrm{OC}$ reflex strength deficits (Fig. 8) and the lack of compensation using electrical stimulation of MOC fibers in $\alpha 9$-nAChR KO mice (Vetter et al., 1999) and in frequency selectivity of brainstem neurons (Clause et al., 2014) support the conclusion that brainstem functions cannot be compensated in $\alpha 9$-nAChR KO mice, whereas cognitive functions such as filtering irrelevant stimuli during attention can be compensated for by other brain circuits (May et al., 2002).

Contralateral noise suppression of wave I in WT and KO mice In agreement with behavioral auditory thresholds obtained in $\alpha 9$-nAChR KO and WT mice (Prosen et al., 2000) and with previous ABR measurements at 8 and $16 \mathrm{kHz}$ (Lauer and May, 2011), in the present study, $\mathrm{ABR}$ thresholds at $15 \mathrm{kHz}$ tones were similar in WT and $\mathrm{KO}$ mice. Therefore, behavioral differences in the auditory distractors across genotypes cannot be attributed to differences in auditory sensitivity.

In our experiments performed in anesthetized animals, we found that WT mice have larger contralateral noise suppressions of ABR wave-I compared with $\mathrm{KO}$ mice (Fig. 8). Although this result is in agreement with the effects obtained with contralateral suppression of DPOAEs in awake WT and $\alpha 9$-nAChR KO mice (Chambers et al., 2012), our effects are larger than those reported in anesthetized mice with DPOAEs (Chambers et al., 2012). Because it is known that anesthesia reduces the effects of contralateral noise on cochlear and auditory nerve responses (Chambers et al., 2012; Aedo et al., 2015), differences between the effects obtained in the anesthetized condition in Chambers et al. (2012) and in our work could be attributed to the fact that olivocochlear effects are larger when evaluated with neural responses compared with DPOAEs (Puria et al., 1996; Lichtenhan et al., 2016). Therefore, the measurement of ABR-wave I suppression with contralateral noise in anesthetized mice can be proposed as an easier technique for testing the olivocochlear reflex in anesthetized animals than measuring DPOAEs in awake conditions (Chambers et al., 2012).

There was a negative correlation between the strength of the olivocochlear reflex and the number of omitted responses during the period of selective attention to visual stimuli with $\mathrm{C}+\mathrm{T}$ distractors (Fig. $8 E$ ). This could suggest that, when MOC activity is strong during the presentation of auditory distractors, these auditory stimuli can be efficiently ignored and thus mice have fewer omitted trials. Another possibility to explain this correlation is that normal MOC activity could help to reduce the overall effort needed to suppress auditory distractors (Shinn-Cunningham and Best, 2008). However, the latter mechanism seems less probable because there were no significant differences between genotypes in the slopes of the omissions along blocks, showing that the effort was probably similar between genotypes. Finally, the lack of difference between the strength of the OC reflex in altered and compensated $\mathrm{KO}$ (Fig. 8C) suggest that the behavioral compensation observed in a subset of $\mathrm{KO}$ mice is not due to the release of other MOC neurotransmitters, but rather to other mechanisms.

\section{Conclusions}

We demonstrate that $\alpha 9$-nAChR KO mice have a diminished strength of the olivocochlear reflex and perform poorly in a visual selective attention paradigm with auditory distractors. These results show that an intact medial olivocochlear transmission aids in ignoring auditory stimuli during selective attention to visual stimuli.

\section{References}

Aboitiz F, Ossandón T, Zamorano F, Palma B, Carrasco X (2014) Irrelevant stimulus processing in ADHD: catecholamine dynamics and attentional networks. Front Psychol 5:183. CrossRef Medline

Aedo C, Tapia E, Pavez E, Elgueda D, Delano PH, Robles L (2015) Stronger efferent suppression of cochlear neural potentials by contralateral acoustic stimulation in awake than in anesthetized chinchilla. Front Syst Neurosci 9:21. CrossRef Medline

Allen Institute for Brain Science (2012) Allen developing mouse brain atlas. Available from: http://www.brain-map.org.

Borg E, Counter SA (1989) The middle-ear muscles. Sci Am 261:74-80. Medline

Broadbent, D (1958) Perception and communication. London: Pergamon. Chambers AR, Hancock KE, Maison SF, Liberman MC, Polley DB (2012) Sound-evoked olivocochlear activation in unanesthetized mice. J Assoc Res Otolaryngol 13:209-217. CrossRef Medline 
Clause A, Kim G, Sonntag M, Weisz CJ, Vetter DE, Rúbsamen R, Kandler K (2014) The precise temporal pattern of prehearing spontaneous activity is necessary for tonotopic map refinement. Neuron 82:822-835. CrossRef Medline

Cooper NP, Guinan JJ Jr (2003) Separate mechanical processes underlie fast and slow effects of medial olivocochlear efferent activity. J Physiol 548: 307-312. CrossRef Medline

Delano PH, Elgueda D, Hamame CM, Robles L (2007) Selective attention to visual stimuli reduces cochlear sensitivity in chinchillas. J Neurosci 27 : 4146-4153. CrossRef Medline

Dragicevic CD, Aedo C, León A, Bowen M, Jara N, Terreros G, Robles L, Delano PH (2015) The olivocochlear reflex strength and cochlear sensitivity are independently modulated by auditory cortex microstimulation. J Assoc Res Otolaryngol 16:223-240. CrossRef Medline

Elgoyhen AB, Johnson DS, Boulter J, Vetter DE, Heinemann S (1994) Alpha 9: an acetylcholine receptor with novel pharmacological properties expressed in rat cochlear hair cells. Cell 79:705-715. CrossRef Medline

Elgoyhen AB, Vetter DE, Katz E, Rothlin CV, Heinemann SF, Boulter J (2001) Alpha10: a determinant of nicotinic cholinergic receptor function in mammalian vestibular and cochlear mechanosensory hair cells. Proc Natl Acad Sci U S A 98:3501-3506. CrossRef Medline

Elgueda D, Delano PH, Robles L (2011) Effects of electrical stimulation of olivocochlear fibers in cochlear potentials in the chinchilla. J Assoc Res Otolaryngol 12:317-327. CrossRef Medline

Fritz JB, Elhilali M, David SV, Shamma SA (2007) Auditory attention-focusing the searchlight on sound. Curr Opin Neurobiol 17:437-455. CrossRef Medline

Gilbert CD, Sigman M (2007) Brain states: top-down influences in sensory processing. Neuron 54:677-696. CrossRef Medline

Guinan JJ Jr (1996) Physiology of olivocochlear efferents. In: The cochlea (Dallos P, Popper A, Fay R eds), pp 435-502. New York: Springer.

Hamame CM, Delano PH, Robles L (2006) Relevance of a neutral cue in a two-choice detection task in the rat. Biol Res 39:259-267. Medline

Hamame CM, Delano PH, Robles L (2008) A neutral cue facilitates detection of a visual target by modulating attention. Biol Res 41:473-479. CrossRef Medline

Hernández-Peón R, Scherrer H, Jouvet M (1956) Modification of electric activity in cochlear nucleus during attention in unanesthetized cats. Science 123:331-332. CrossRef Medline

Katz E, Elgoyhen AB (2014) Short-term plasticity and modulation of synaptic transmission at mammalian inhibitory cholinergic olivocochlear synapses. Front Syst Neurosci 8:224. CrossRef Medline

Kong WJ, Cheng HM, van Cauwenberge P (2006) Expression of nicotinic acetylcholine receptor subunit alpha9 in type II vestibular hair cells of rats. Acta Pharmacol Sin 27:1509-1514. CrossRef Medline

Lauer AM, May BJ (2011) The medial olivocochlear system attenuates the developmental impact of early noise exposure. J Assoc Res Otolaryngol 12:329-343. CrossRef Medline

León A, Elgueda D, Silva MA, Hamamé CM, Delano PH (2012) Auditory cortex basal activity modulates cochlear responses in chinchillas. PLoS One. 7:e36203. CrossRef Medline

Lichtenhan JT, Wilson US, Hancock KE, Guinan JJ Jr (2016) Medial olivocochlear efferent reflex inhibition of human cochlear nerve responses. Hear Res 333:216-224. CrossRef Medline

Maison SF, Adams JC, Liberman MC (2003) Olivocochlear innervation in the mouse: immunocytochemical maps, crossed versus uncrossed contributions, and transmitter colocalization. J Comp Neurol 455:406-416. CrossRef Medline
May BJ, Prosen CA, Weiss D, Vetter D (2002) Behavioral investigation of some possible effects of the central olivocochlear pathways in transgenic mice. Hear Res 171:142-157. CrossRef Medline

McIntosh JM, Absalom N, Chebib M, Elgoyhen AB, Vincler M (2009) Alpha9 nicotinic acetylcholine receptors and the treatment of pain. Biochem Pharmacol 78:693-702. CrossRef Medline

Melki SJ, Li Y, Semaan MT, Zheng QY, Megerian CA, Alagramam KN (2014) A mouse model validates the utility of electrocochleography in verifying endolymphatic hydrops. J Assoc Res Otolaryngol 15:413-421. CrossRef Medline

Mishra J, de Villers-Sidani E, Merzenich M, Gazzaley A (2014) Adaptive training diminishes distractibility in aging across species. Neuron 84: 1091-1103. CrossRef Medline

Murugasu E, Russell IJ (1996) The effect of efferent stimulation on basilar membrane displacement in the basal turn of the guinea pig cochlea. J Neurosci 16:325-332. Medline

Oatman LC (1971) Role of visual attention on auditory evoked potentials in unanesthetized cats. Exp Neurol 32:341-356. CrossRef Medline

Prosen CA, Bath KG, Vetter DE, May BJ (2000) Behavioral assessments of auditory sensitivity in transgenic mice. J Neurosci Methods 97:59-67. CrossRef Medline

Prut L, Belzung C (2003) The open field as a paradigm to measure the effects of drugs on anxiety-like behaviors: a review. Eur J Pharmacol 463:3-33. CrossRef Medline

Puria S, Guinan JJ Jr, Liberman MC (1996) Olivocochlear reflex assays: effects of contralateral sound on compound action potentials versus earcanal distortion products. J Acoust Soc Am 99:500-507. CrossRef Medline

R Core Team (2014) R: a language and environment for statistical computing. R Foundation for Statistical Computing, Vienna. Available from: http://www.R-project.org.

Robles L, Delano PH (2008) Efferent system. In: The senses: a comprehensive reference (Dallos P and Oertel D eds), pp 413-445. London: Academic.

Shinn-Cunningham BG, Best V (2008) Selective attention in normal and impaired hearing. Trends Amplif 12:283-299. CrossRef Medline

Terreros G, Delano PH (2015) Corticofugal modulation of peripheral auditory responses. Front Syst Neurosci 9:134. CrossRef Medline

Valero MD, Hancock KE, Liberman MC (2016) The middle ear muscle reflex in the diagnosis of cochlear neuropathy. Hear Res 332:29-38. CrossRef Medline

Vetter DE, Liberman MC, Mann J, Barhanin J, Boulter J, Brown MC, SaffioteKolman J, Heinemann SF, Elgoyhen AB (1999) Role of alpha9 nicotinic $\mathrm{ACh}$ receptor subunits in the development and function of cochlear efferent innervation. Neuron 23:93-103. CrossRef Medline

Vetter DE, Katz E, Maison SF, Taranda J, Turcan S, Ballestero J, Liberman MC, Elgoyhen AB, Boulter J (2007) The alpha10 nicotinic acetylcholine receptor subunit is required for normal synaptic function and integrity of the olivocochlear system. Proc Natl Acad Sci U S A 104:20594-20599. CrossRef Medline

Walsh KP, Pasanen EG, McFadden D (2015) Changes in otoacoustic emissions during selective auditory and visual attention. J Acoust Soc Am 137:2737-2757. CrossRef Medline

Warr WB, Guinan JJ Jr (1979) Efferent innervation of the organ of corti: two separate systems. Brain Res 173:152-155. CrossRef Medline

Wittekindt A, Kaiser J, Abel C (2014) Attentional modulation of the inner ear: a combined otoacoustic emission and EEG study. J Neurosci 34: 9995-10002. CrossRef Medline 